\title{
Water turbidity constrains male mating success in a marine fish
}

\author{
Marja Järvenpää ${ }^{1} \cdot$ Beatriz Diaz Pauli ${ }^{1} \cdot$ Kai Lindström ${ }^{1}$ (D)
}

Received: 20 June 2019 / Revised: 2 September 2019 / Accepted: 13 September 2019 / Published online: 25 October 2019

(C) The Author(s) 2019

\begin{abstract}
Human-induced eutrophication, resulting in increased algal growth and water turbidity, is an alarming problem in aquatic systems. Many studies have focused on the effects of algal turbidity on mate choice and sexual selection in fish, but little emphasis has been given to the ways it can constrain mating success. Here we experimentally investigated the effects of algal turbidity on maximum male mating success and parental care in the sand goby, Pomatoschistus minutus, a fish with a resourcedefence mating system and male parental care. For this purpose, we introduced to 1 nest-holding male 5 random-sized ripe females in either clear or in turbid water. After spawning, we observed how many mates and eggs the male received and followed his parental behaviour and egg survival for 6 days under turbid or clear water conditions. When spawning took place in clear water, the number of eggs the male received into his nest increased with the total weight of five females in his tank. However, when spawning took place in turbid water, there was no relationship between female size and the number of eggs laid, although the number of females that spawned was the same as in clear water. The results indicate that females adjust the number of eggs they lay according to water turbidity. This could explain previous findings that mating success is more evenly distributed among males in turbid than clear water conditions.
\end{abstract}

\section{Significance statement}

The first responses of animals to human-induced changes in the environment are behavioural. Subtle changes in the behaviour of individuals can have profound consequences for populations and communities. Human-induced eutrophication, leading to algal blooms and water turbidity, is a major environmental problem in aquatic systems worldwide. Our results on the sand goby suggest a new mechanism by which water turbidity may affect fish mating systems and weaken sexual selection. When spawning takes place in clear water, the number of eggs accumulated in a males' nest is an increasing function of the fecundity of the females. However, when spawning in turbid water, this positive relationship between female size and egg numbers disappears. We believe this is because females do not perceive the competition from other females in turbid water and therefore invest less in present reproduction.

Keywords Sexual selection $\cdot$ Mating competition $\cdot$ Parental care $\cdot$ Eutrophication $\cdot$ Mating system

\section{Introduction}

Environmental changes of anthropogenic origin constitute various challenges to animal populations. Many of these, such as anthropogenic noise (Gordon and Uetz 2012; Schmidt et al. 2014; Huet des Aunay et al. 2017) or the persistence of

Communicated by I. Hamilton

Kai Lindström

Kai.Lindstrom@abo.fi

1 Environmental and Marine Biology, Åbo Akademi University, FIN-20520 Turku, Finland chemical signals in a warming environment (Martín and López 2013), interfere with the natural breeding behaviour of wildlife, often by changing the prerequisites for successful sexual signalling. In aquatic environments, a major anthropogenic change is eutrophication, with more than 400 eutrophicated coastal systems having been identified globally (Selman et al. 2008). One consequence of eutrophication is deteriorating water clarity due to increased growth of planktonic algae. In fish, such human-induced water turbidity has been shown to increase hybridization among species (Seehausen et al. 1997), to weaken sexual selection (Järvenpää and Lindström 2004; Engström-Öst and Candolin 2007) and to decrease parental care (Candolin et al. 2008; Järvenpää and Lindström 2011; Wong et al. 
2012). It has also been found to lower foraging success (UtnePalm 2002; Sohel et al. 2017) and hamper schooling behaviour (Fischer and Frommen 2013), as well as predator avoidance (Sohel and Lindström 2015).

Although many studies have focused on how turbidity affects mate choice and sexual selection, no previous studies that we are aware of have examined the constraints that environmental change may have on the maximum mating success an individual attains. In an earlier study on the sand goby, Pomatoschistus minutus, a fish species where males defend nests and provide parental care to the eggs, we found that mating success (number of mates and eggs) is more evenly distributed among males in turbid water than in clear water (Järvenpää and Lindström 2004). This result could be at least partially explained if males in turbid water accept or attract fewer females or females avoid spawning with males guarding a large number of eggs. One reason for males to cease courting additional females could be the cost of care for a very large brood. Algal turbidity leads to increased silt formation, which could be harmful for the developing eggs (Potts et al. 1988; Gray et al. 2012). A characteristic of male parental care behaviour in fish is fanning. Fanning is thought to oxygenate the eggs, to disperse chemical signals, and to remove silt and waste products (Potts et al. 1988; Green and McCormick 2005; Meunier et al. 2013). Larger egg clutches need more oxygen, so they also increase the need for fanning (van Iersel 1953; Reebs et al. 1984; Coleman and Fischer 1991; Lindström and Wennström 1994). Therefore, with increasing siltation, the need for fanning and hence the cost to the caring parent still increases and may eventually outweigh the benefits of an increased clutch size.

Another possibility for a more even distribution of mating success among males in turbid water is that under adverse environmental conditions, females avoid spawning with already mated males. For example, under normal oxygen conditions, common goby females prefer already mated males but when oxygen is low, they avoid these males (Reynolds and Jones 1999). Of course, it is also possible that turbidity affects both male and female behaviour simultaneously resulting in more even distribution of matings among males.

Here we describe a study designed to examine whether turbidity imposes a mating cost on males and females such that the number of mates and eggs a male obtains is lower under turbid, compared with clear water. We also investigate if turbidity affects male parental behaviour and if the survival of large egg clutches is different in turbid than in clear water conditions. As a model system, we use the sand goby (Pomatoschistus minutus). The sand goby is a small marine fish species with a resource-defence mating system and male parental care. The male builds a nest under a suitable substrate, such as a mussel shell or a stone, and attracts females to spawn in it. Females lay their eggs in a single layer in the ceiling of the nest and leave the nest after spawning. The male then alone cares for the eggs until they hatch. Egg fanning and protecting the nest against intruders are major parts of care. One male can guard eggs from multiple females simultaneously if his nest is large enough. There is extensive background information on the sand goby reproductive system and behaviour (see e.g., Forsgren 1999; Lehtonen 2012), which provides an excellent basis for studies that want to explore the effects of environmental changes on reproduction.

In this study, we examined the effects of algal turbidity on male maximal mating success and parental care. We allowed individual males to spawn with several females in either clear or turbid water. Males then cared for the eggs in clear or in turbid conditions. We predicted that if turbidity has a negative effect on the number of eggs males are willing, or able to attract, then males should accumulate smaller egg clutches when spawning takes place in turbid water. If turbidity hampers parental care, we expect males to lose more eggs under turbid than clear water conditions.

\section{Material and methods}

This study was done at Tvärminne Zoological station in 2006 during the sand goby breeding season. The males for the experiments were caught from a nearby breeding area (Vargskär), whereas females were caught in various locations around the station using a small hand trawl. In the lab, fish were housed in separate-sex storage tanks with a continuous flow through of fresh seawater and fed ad libitum with live Mysis relicta and frozen chironomid larvae. Because the tanks were placed in an outdoor lab with transparent walls and roof, they had natural light conditions.

The experimental aquaria, measuring $70 \mathrm{~cm} \times 25 \mathrm{~cm} \times$ $35 \mathrm{~cm}(l \times w \times h)$, were set in the same outdoor lab. In front of the aquaria, we placed blinds equipped with peepholes to allow for observations with minimal disturbance to fish. Each tank had a 4-cm layer of fine sand on the bottom and a halved clay flowerpot placed in the middle of the tank to serve as a nest site. Because sand goby females lay their eggs in a single layer in the ceiling of the nest cavity, the area of the nest substrate largely determines the number of females that could place their eggs in the same nest simultaneously (Lindström 1992). To ensure adequate spawning space, we used flowerpots of $10 \mathrm{~cm}$ in diameter, which can easily accommodate eggs from five females (KL pers. obs.). We placed a piece of acetate sheet, cut into the shape of the nest, into the ceiling of each nest. Any eggs laid in the nest would attach to the sheet and could be gently removed from the nest for photographing and put back in place afterwards. 


\section{Experimental treatments}

Our experiment had two treatments with two levels each. The treatments differed with respect to whether water was clear (C) or turbid (T) and whether water quality was changed before (B) or after (A) spawning (Fig. 1). In all the treatments, the focal male was first allowed to construct a nest in clear water for 24 hours. After this, five random-sized ripe females with clearly rounded bellies were introduced to the male. There was no difference among treatments in the average length (ANOVA, all $F_{1,54}<0.372$, all $p=\mathrm{NS}$ ) or weight (all $F_{1,54}<$ 0.876 , all $p=\mathrm{NS}$ ) of the five females. Females were introduced to males either before or after the water change (Fig. 1). Consequently, in the treatment with turbid water change before spawning (TB), spawning took place in turbid water while in all other treatments, spawning took place in clear water. In both the TB and the turbid water change after spawning (TA) treatments, parental care took place in turbid water. The clear water change before spawning $(\mathrm{CB})$ and the clear water change after spawning (CA) treatments acted as controls for the previous two and remained clear throughout the experiment. Females were allowed 24 hours to spawn; after which, they were removed and their spawning status was assessed based on their roundness. Spawned females can be identified by their slim bellies. After this, the females were released back to their natural breeding area. After spawning, the acetate sheet lining inside of the nest was removed, photographed, and carefully returned to the nest. The number of eggs spawned was counted from the digital images.

Males were left in the tanks to care for the eggs during which time, they were fed one chironomid larva daily. Their parental behaviour was observed on days two and six of the parental phase (see Järvenpää and Lindström 2011). We recorded the time spent fanning during a 10-minute observation period. To minimize observer bias, the observer was blind to the treatment when behavioural data were recorded. After each observation, the eggs in the nests were photographed and counted. On day six, after the last observation, the replicates were finished, and the fishes were released back to their natural breeding area.

The water in the TB and TA treatments was made turbid by adding a mixture of clear seawater and unicellular planktonic algae, Brachiomonas submarina (Järvenpää and Lindström 2004). Water turbidity values (nephelometric turbidity units) in the $\mathrm{CB}, \mathrm{CA}, \mathrm{TB}$, and $\mathrm{TA}$ treatments were on average $=0.87(\mathrm{SD}=0.35, n=10), 1.04(\mathrm{SD}=$ $0.42, n=10), 3.66(\mathrm{SD}=1.03, n=19)$, and $3.26(\mathrm{SD}=$ $1.01, n=18)$, respectively.

\section{Experiment phase}

A

TB

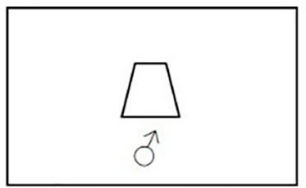

CB

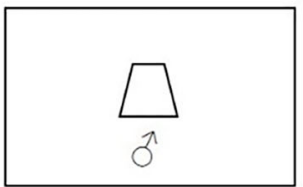

TA

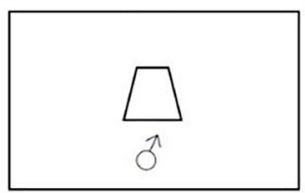

CA
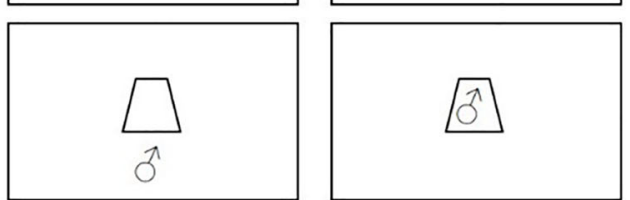

Fig. 1 The experimental design. (A) Males were allowed to build nests in clear water for 24 hours. (B) After nest building, water in the turbid before spawning (TB) treatment was made turbid by adding a mixture of cultivated planktonic algae and fresh seawater. An equivalent amount of fresh seawater was added to the clear before spawning (CB) treatment. (C) Five ripe females of random size were introduced to each male and allowed 24 hours to spawn. (D) After spawning, females were removed from the tanks and eggs were photographed. Water in the turbid after
C

D
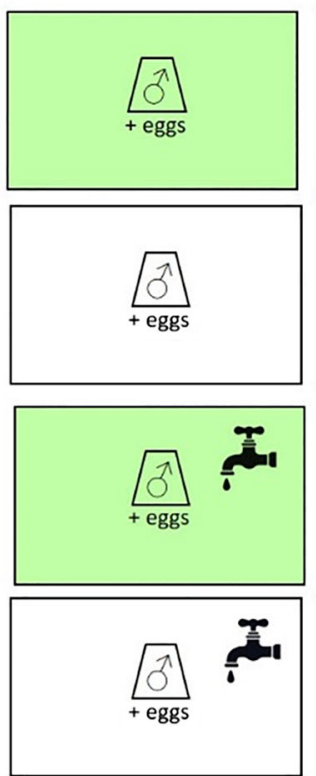

E
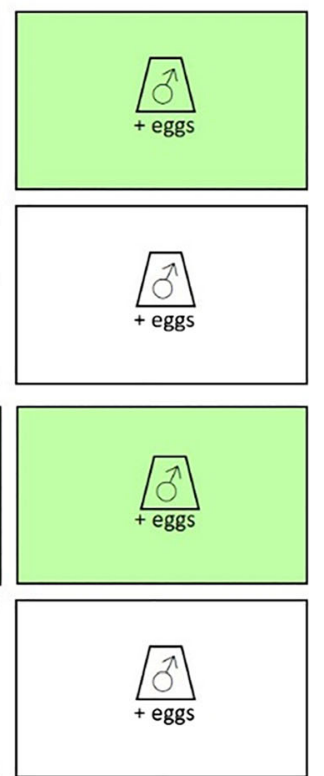

spawning (TA) treatment was now made turbid by adding a mixture of planktonic algae and fresh seawater. Clear after spawning (CA) treatment received an equal amount of fresh sea water. Males were left in the tanks to care for their eggs. (E) Male parental behaviour was observed for $10 \mathrm{~min}$ on the next day, day 2 of parental phase, and again on day 6 . After observations, the eggs were photographed and counted from the images 
We started in total 58 replicates $(\mathrm{CB}, n=10$; CA, $n=10$; TB, $n=19$; TA, $n=19$ ) that are all included in the analyses on initial egg numbers. The sample size for egg survival (CB, $n=$ 9; CA, $n=9$; TB, $n=13$; TA, $n=15$ ) and behavioural analyses (day 2: $\mathrm{CB}, n=9$; $\mathrm{CA}, n=9$; TB, $n=18$; TA, $n=17$; day 6: $\mathrm{CB}, n=8$; CA, $n=6$; TB, $n=13$; TA, $n=13$ ) is smaller because 9 males died before day 6 when the experiment ended. Sand gobies live only for one breeding season (Healey 1971; Fonds 1973) and therefore, natural deaths are frequent during the season. Three additional replicates were excluded from the egg survival analysis because the egg pictures were lost.

\section{Statistical analyses}

To analyse the effect of the water treatments (fixed factor) on the number of females that spawned, we applied a generalized linear models (GLZ) with a Poisson error distribution and log link function. The number of eggs spawned fulfilled the requirements of parametric tests. Therefore, to analyse the number of eggs spawned, we used a parametric ANCOVA with female weight as a covariate. Female weight was the sum of all five females' weights, because we assume that this is a good representation of their combined fecundity. The effect of turbidity on the number of eggs spawned was tested by comparing the treatment where the water was turbid before spawning (TB) to the pooled treatments where the water was clear during spawning (CB, CA, and TA).

To test the effect of turbidity on parental care (time spent fanning the eggs) and egg survival, we compared the treatment where the water was made turbid after spawning (TA) with the control where a water change from clear to clear was done after spawning (CA). The time spent fanning the eggs on days 2 and 6 was analysed using a GLZ with a linear error distribution and identity link function. Egg survival was measured as the number of eggs left on day 6 using the initial number of eggs as a covariate. For the analysis, we excluded replicates with total filial cannibalism $(n=6)$ and included only those which still had eggs on day $6(n=17)$. We used a GLZ with a linear error distribution and identity link function. All analyses were done using SPSS v 23 statistical software.

\section{Data availability}

The datasets analysed during the current study are available from the corresponding author on reasonable request.

\section{Results}

On average, about four females spawned both in turbid and clear water (GLZ with Poisson error distribution and log link function, Wald $X^{2}=0.02$, $\mathrm{df}=1, p=0.889$; Fig. 2). The

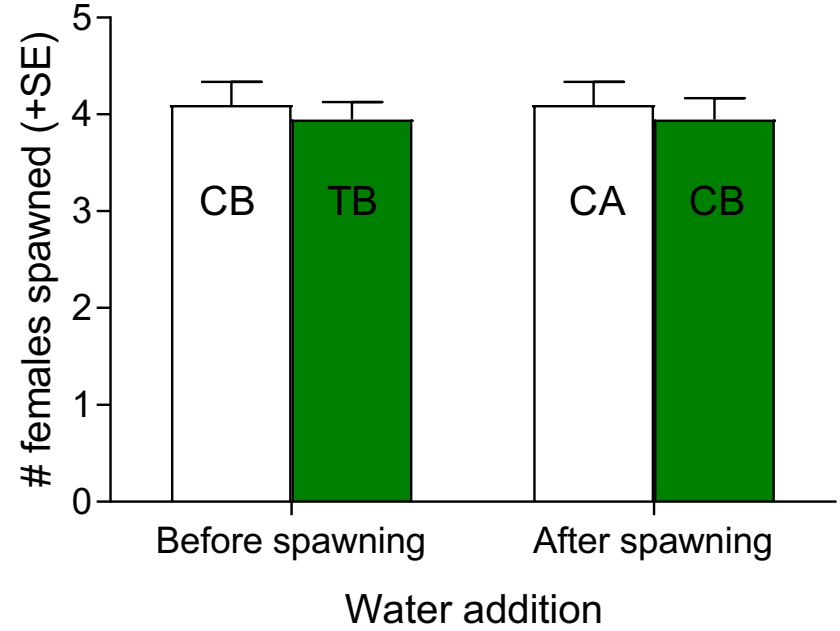

Fig. 2 The number of females that spawned $($ mean $+\mathrm{SE})$ in the different treatments. Abbreviations in bars: see legend of Fig. 1

average number of eggs spawned was 3206 (SD $=1198, n=$ 58 ) with more eggs spawned in clear water than in turbid water (GLZ, Wald $X^{2}=8.033, \mathrm{df}=1, p=0.005$; Fig. 3). The number of eggs spawned increased with total female weight (Wald $X^{2}=6.349, \mathrm{df}=1, p=0.012$; Fig. 3). However, there was an interaction effect between total female weight and the number of eggs spawned (interaction effect between female weight and treatment, Wald $X^{2}=5.501, \mathrm{df}=1, p=0.019$ ). The relationship between female total weight and number of eggs spawned was present when spawning in clear water only, while in turbid water, this relationship was absent (Fig. 3).

\section{Parental care and egg survival}

There were no differences among treatments in the time spent fanning either on day 2 (GLZ with linear error, Wald $X^{2}=$ $0.003, \mathrm{df}=1, p=0.958$ ) or day 6 (Wald $X^{2}=0.219, \mathrm{df}=1$, $p=0.639$ ).

In the treatment where the water was made turbid before the parental phase (TA), three out of 15 egg clutches were completely consumed by the parental male. This is similar to the control treatment (CA) where the clear water was replaced by clear water before the parental phase and the males consumed 4 out of 9 clutches (Likelihood ratio $=$ 1.597 , df $=1, p=0.356$ ). Completely consumed clutches were on average smaller than partially cannibalized clutches (GLZ, Wald $X^{2}=5.034$, df $=1, p=0.025$, Fig. 4). Among the successful clutches, the number of eggs that reached day 6 depended only on the initial number of eggs (GLZ, covariate initial eggs, Wald $X^{2}=8.381$, df $=1, p=$ 0.004 ), while it was unaffected by water quality (Wald $\left.X^{2}=0.006, \mathrm{df}=1, p=0.939\right)$ and the interaction between the initial egg number and water quality (Wald $X^{2}=0.042$, $\mathrm{df}=1, p=0.837$ ). 
Fig. 3 The initial number of eggs spawned as a function of total female weight. Total female weight is the sum of all five females' weights. "Turbid" stands for the treatment in which spawning took place in turbid water whereas "Clear" is for the treatments in which spawning took place in clear water

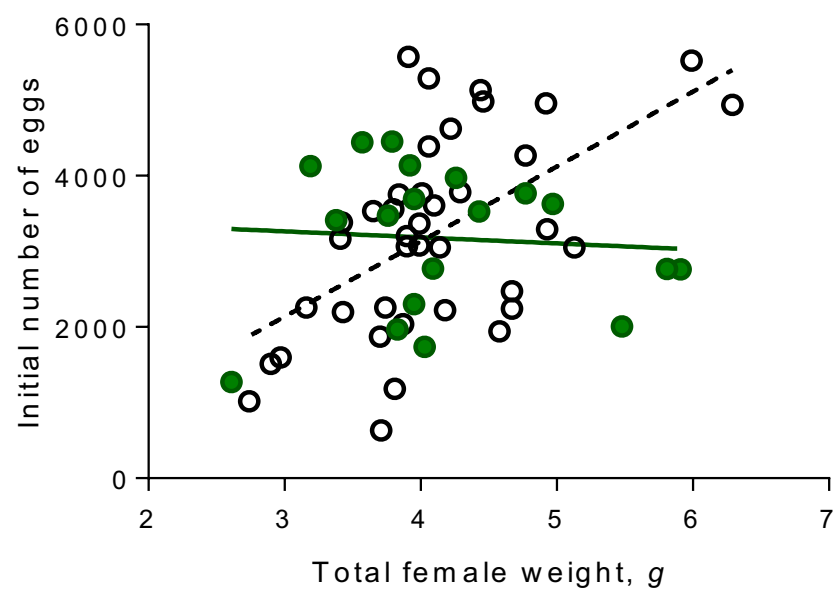

In female fish, size and fecundity often correlate strongly, i.e., larger and heavier females lay more eggs (Bagenal 1967). Some species have been shown to adjust the number of eggs laid as a short-term response to competing females (Heubel et al. 2008) and the quality of the male (Evans et al. 2010; Moshgani and Van Dooren 2011), suggesting that females have much control over the way they partition their reproductive output. The fact that the number of eggs did not increase with female size in the turbid treatment-although the number of spawned females was the same as in other treatmentssuggests that females did not spawn all their eggs in these conditions.

In theory, it is also possible that the males limited the number of mates or eggs in the constantly turbid treatment. This could have happened if the costs of attracting further females and/or taking care of the larger brood exceeded the benefits achieved or if there was a stronger trade-off between courting and care in turbid water (Järvenpää and Lindström 2011). Egg numbers could also have been limited if males prematurely interrupted spawning or through an increase in filial cannibalism. However, such possibilities do not appear to explain the patterns observed in the current study. Specifically, we found that the number of females that spawned was similar for each treatment, indicating that males continued attracting females to their nests as they received additional matings. Also, we found that males were fanning their eggs equally much in turbid and in clear water, and the egg and clutch survival was similar in all the treatments suggesting that males did equally well with large clutches in both conditions. Male fish, including sand gobies, are known to sometimes consume their own viable eggs (Rohwer 1978; Sargent 1992; Klug and Lindström 2008). If the costs of care in turbid water had been too high, males could always have eaten part of or all their nutritious eggs. However, the number of eggs at the end of the care period was similar in all treatments and was only a function of the initial egg number. Consequently, we conclude that the limited number of eggs in turbid water was not due to male behaviour but, instead, appears to be driven by female spawning decisions.
Fig. 4 The mean size + SE of partially and completely cannibalized clutches 
So, why was the positive relationship between female size and the number of eggs laid absent in turbid water? One possibility is that females found turbid conditions unfavourable and adjusted the number of eggs they laid accordingly. In the closely related common gobies, females prefer already mated males under normal oxygen conditions but when oxygen is low, they avoid these males (Reynolds and Jones 1999). Reynolds and Jones (1999) suggested that this may be due to females avoiding males that would be unable to take care of a larger clutch under low oxygen. Similarly, female sand gobies could have avoided spawning with mated males in turbid water if algal turbidity required excess parental effort from the males. Here, the females did not have a chance to choose between males so if they wanted to adjust their reproductive allocation, the only way to do so was to adjust the amount of eggs laid. There are no published data on the ability of sand goby females to adjust the number of eggs spawned in response to prevailing conditions, yet we have repeatedly observed that sometimes, females split their egg clutches between two males' nests (MJ and KL pers. obs.). However, evidence exists that females can adjust the number of eggs spawned in other fish species (Evans et al. 2010; Moshgani and Van Dooren 2011) including the closely related common goby (Heubel et al. 2008). In the common goby, females have been shown to lay larger clutches in the presence of other females (Heubel et al. 2008). Therefore, it is possible that our present results could be explained by female competition for spawning space. In clear water, detecting and assessing competing females may be easier than in turbid water where visibility is hampered, and competition might not be apparent. In male sticklebacks, for example, turbidity reduces aggressive interactions, possibly due to reduced visibility (Wong et al. 2007). If turbidity hampers the detection of competing females, this could lead to females adjusting their egg masses according to the competitive situation in clear but not in turbid water.

In the present study, turbidity had no effect on male fanning behaviour or egg survival. Earlier, we have shown that in turbid water, eggs survive better despite males fanning less and spending more time away from the nest early in the care period (Järvenpää and Lindström 2011). These results suggested that fanning in the beginning of the care period might function mostly as courtship instead of care and that due to low visibility males in turbid water may experience a trade-off between fanning and mate search. In addition, stickleback males fan their eggs less in turbid water but have a higher hatching success than males in clear water (Candolin et al. 2008). Why was this not the case in this study? One reason could be that in this study, egg masses, which consisted of on average 4 females' eggs, were very large, which may have required particularly high parental effort by the male. Furthermore, the high female density in this study might have mitigated the potentially increased trade-off between fanning and mate search in turbid conditions, as males would not have to leave their nest to encounter additional females. Finally, the fitness value of a large egg mass may be perceived such that males decide to invest in care rather than mate attraction (Williams 1966; Sargent and Gross 1985). The value of large egg masses is manifested for example in the patterns of filial cannibalism. It is typically small clutches that are consumed (Lindström and Sargent 1997; Klug 2009) whereas large clutches are cared for, and this was also the case in this study.

In conclusion, we found that when females spawned in clear water, the number of eggs increased with total female weight. However, when spawning took place in turbid water, there was no relationship between female size and the number of eggs laid. We suggest that this was due to a female decision to adapt spawning to water quality rather than a male decision to adjust the number of eggs in his nest. Our results emphasize how anthropogenic impacts can impair reproductive success of individuals, which, in turn, is central for population persistence.

Acknowledgments We thank Tvärminne zoological station for providing excellent working facilities. We also thank Maria Järvi-Laturi, Topi Lehtonen, and Bob Wong for help in the field and lab. Topi Lehtonen, Bob Wong, and Hannu Pietiäinen provided insightful comments on previous versions of this manuscript. We are grateful to two anonymous reviewers for their constructive comments that greatly improved our manuscript. Open access funding provided by Abo Akademi University (ABO).

Funding information This work was financially supported by the Academy of Finland grant number 211973 (to KL) and the Evolutionary Ecology graduate school and Onni Talas foundation (to MJ).

\section{Compliance with ethical standards}

Conflict of interest The authors declare that they have no conflicts of interest.

Ethical approval We have followed all applicable EU and national guidelines for the care and use of animals. This study has been approved by the University of Helsinki animal housing authorities, permit no. HY 46-03.

Open Access This article is distributed under the terms of the Creative Commons Attribution 4.0 International License (http:// creativecommons.org/licenses/by/4.0/), which permits unrestricted use, distribution, and reproduction in any medium, provided you give appropriate credit to the original author(s) and the source, provide a link to the Creative Commons license, and indicate if changes were made.

\section{References}

Bagenal TB (1967) A short review of fish fecundity. In: Gerking SD (ed) The biological basis of freshwater fish production. Blackwell Scientific Publishers, Oxford, pp 89-111

Candolin U, Engström-Öst J, Salesto T (2008) Human-induced eutrophication enhances reproductive success through effects on parenting ability in sticklebacks. Oikos 117:459-465 
Coleman RM, Fischer RU (1991) Brood size, male fanning effort and the energetics of a nonshareable parental investment in bluegill sunfish, Lepomis macrochirus (Teleostei: Centrarchidae). Ethology 87:177188

Engström-Öst J, Candolin U (2007) Human-induced water turbidity alters selection on sexual displays in sticklebacks. Behav Ecol 18:393-398

Evans JP, Box TM, Brooshooft P, Tatler JR, Fitzpatrick JL (2010) Females increase egg deposition in favor of large males in the rainbowfish, Melanotaenia australis. Behav Ecol 21:465-469

Fischer S, Frommen JG (2013) Eutrophication alters social preferences in three-spined sticklebacks (Gasterosteus aculeatus). Behav Ecol Sociobiol 67:293-299

Fonds M (1973) Sand gobies of the Dutch Wadden Sea (Pomatoschistus, Gobiidae, Pisces). Neth J Sea Res 6:417-478

Forsgren E (1999) Sexual selection and sex roles in the sand goby. In: Almada VC, Oliveira RF, Goncalves EJ (eds) Behaviour and conservation of littoral fishes. ISPA, Lisboa, pp 249-274

Gordon SD, Uetz GW (2012) Environmental interference: impact of acoustic noise on seismic communication and mating success. Behav Ecol 23:707-714

Gray S, Chapman L, Mandrak N (2012) Turbidity reduces hatching success in threatened spotted gar (Lepisosteus oculatus). Environ Biol Fish 94:689-694

Green BS, McCormick MI (2005) $\mathrm{O}_{2}$ replenishment to fish nests: males adjust brood care to ambient conditions and brood development. Behav Ecol 16:389-397

Healey MC (1971) The distribution and abundance of sand gobies Gobius minutus, in the Ythan Estuary. J Zool 163:177-229

Heubel KU, Lindström K, Kokko H (2008) Females increase current reproductive effort when future access to males is uncertain. Biol Lett 4:224-227

Huet des Aunay G, Grenna M, Slabbekoorn H, Nicolas P, Nagle L, Leboucher G, Malacarne G, Draganoiu TI (2017) Negative impact of urban noise on sexual receptivity and clutch size in female domestic canaries. Ethology 123:843-853

Järvenpää M, Lindström K (2004) Water turbidity by algal blooms causes mating system breakdown in a shallow-water fish, the sand goby Pomatoschistus minutus. Proc R Soc Lond B 271:2361-2365

Järvenpää M, Lindström K (2011) Algal blooms decrease care but increase egg survival in a fish with paternal care. Behav Ecol Sociobiol 65:2023-2028

Klug H (2009) The relationship between filial cannibalism, egg energetic content and parental condition in the flagfish. Anim Behav 77: 1313-1319

Klug H, Lindström K (2008) Hurry-up and hatch: Selective filial cannibalism of slower developing eggs. Biol Lett 4:160-162

Lehtonen TK (2012) Signal value of male courtship effort in a fish with paternal care. Anim Behav 83:1153-1161

Lindström K (1992) Female spawning patterns and male mating success in the sand goby Pomatoschistus minutus. Mar Biol 113:475-480

Lindström K, Sargent RC (1997) Food access, brood size and filial cannibalism in the fantail darter, Etheostoma flabellare. Behav Ecol Sociobiol 40:107-110

Lindström K, Wennström C (1994) Expected future reproductive success and paternal behaviour in the sand goby, Pomatoschistus minutus. $\mathrm{J}$ Fish Biol 44:469-477

Martín J, López P (2013) Effects of global warming on sensory ecology of rock lizards: increased temperatures alter the efficacy of sexual chemical signals. Funct Ecol 27:1332-1340
Meunier B, White B, Corkum LD (2013) The role of fanning behavior in water exchange by a nest-guarding benthic fish before spawning. Limnol Oceanogr 3:198-209

Moshgani M, Van Dooren TJM (2011) Maternal and paternal contributions to egg size and egg number variation in the blackfin pearl killifish Austrolebias nigripinnis. Evol Ecol 25:1179-1195

Potts GW, Keenleyside MHA, Edwards JM (1988) The effect of silt on the parental behavior of the sea stickleback, Spinachia spinachia. J Mar Biol Assoc UK 68:277-286

Reebs SG, Whoriskey JFG, FitzGerald GJ (1984) Diel patterns of fanning activity, egg respiration, and the nocturnal behavior of male threespined sticklebacks, Gasterosteus aculeatus L. (f. trachurus). Can J Zool 62:329-334

Reynolds JD, Jones JC (1999) Female preference for preferred males is reversed under low oxygen conditions in the common goby (Pomatoschistus microps). Behav Ecol 10:149-154

Rohwer S (1978) Parent cannibalism of offspring and egg raiding as a courtship strategy. Am Nat 112:429-440

Sargent RC (1992) Ecology of filial cannibalism in fish: theoretical perspectives. In: Elgar MA, Crespi BJ (eds) Cannibalism: ecology and evolution among diverse taxa. Oxford University Press, New York, pp 38-62

Sargent RC, Gross MR (1985) Parental investment decision rules and the Concorde fallacy. Behav Ecol Sociobiol 17:43-45

Schmidt R, Morrison A, Kunc HP (2014) Sexy voices - no choices: male song in noise fails to attract females. Anim Behav 94:55-59

Seehausen O, van Alphen JJM, Witte F (1997) Cichlid fish diversity threatened by eutrophication that curbs sexual selection. Science 277:1808-1811

Selman M, Greenhaldh S, Diaz R (2008) Eutrophication and hypoxia in coastal areas: A global assessment of the state of knowledge. WRI Policy Notes, https://wriorg.s3.amazonaws.com/s3fs-public/pdf/ eutrophication and hypoxia in coastal areas.pdf Accessed 12 Oct 2015

Sohel S, Lindström K (2015) Algal turbidity reduces risk assessment ability of the three-spined stickleback. Ethology 121:548-555

Sohel S, Mattila J, Lindström K (2017) Effects of turbidity on prey choice of three-spined stickleback Gasterosteus aculeatus. Mar Ecol Prog Ser 566:159-167

Utne-Palm AC (2002) Visual feeding of fish in a turbid environment: physical and behavioural aspects. Mar Freshw Behav Physiol 35: $111-128$

van Iersel JJA (1953) An analysis of the parental behaviour of the threespined stickleback (Gasterosteus aculeatus L.). Behav Suppl 3:1159

Williams GC (1966) Natural selection, the cost of reproduction and a refinement of Lack's principle. Am Nat 100:687-690

Wong BBM, Candolin U, Lindström K (2007) Environmental deterioration compromises socially enforced signals of male quality in threespined sticklebacks. Am Nat 170:184-189

Wong BBM, Tuomainen U, Candolin U (2012) Algal blooms impact the quality of nest construction in three-spined sticklebacks. Anim Behav 84:1541-1545

Publisher's note Springer Nature remains neutral with regard to jurisdictional claims in published maps and institutional affiliations. 